\title{
Cardiovascular outcomes associated with crush versus provisional stenting techniques for bifurcation lesions: a systematic review and meta-analysis
}

Feng Huang ${ }^{1 *}$ (1) and Zu-chun Luo ${ }^{2}$

\begin{abstract}
Background: Percutaneous coronary intervention (PCl) for bifurcation lesions has often been challenging for Interventionists. Application of the correct intra-procedural technique is vital to generate beneficial outcomes after $\mathrm{PCl}$. We aimed to systematically compare the post interventional cardiovascular outcomes which were reported using crush versus provisional stenting techniques for bifurcation lesions.

Methods: A computerized search was carried out through Medical Literature Analysis and Retrieval System Online, EMBASE, the Cochrane Central and through www.ClinicalTrials.gov for English publications comparing crush versus the provisional stenting techniques for coronary bifurcation lesions during PCI. Major adverse cardiac events, allcause mortality, cardiac death, myocardial infarction, stent thrombosis, target vessel and target lesion revascularizations were the endpoints in this analysis. Odds ratios (OR) and 95\% confidence intervals (Cl) were generated during statistical analysis to represent the data.

Results: Six studies consisting of a total number of 2220 participants (1085 participants were assigned to the crush stenting technique and 1135 participants were assigned to the provisional stenting technique) enrolled between years 2004 and 2016 were included in this analysis.

During a follow-up time period from six to sixty months, major adverse cardiac events (OR: 0.73, 95\% Cl: 0. 59-0.91; $P=0.005$ ), target vessel revascularization (OR: $0.62,95 \% \mathrm{Cl}: 0.43-0.89 ; P=0.01$ ) and target lesion revascularization (OR: $0.62,95 \% \mathrm{Cl}: 0.45-0.85 ; P=0.003$ ) were significantly lower in patients who were assigned to the crush stenting technique. However, all-cause mortality (OR: $0.90,95 \% \mathrm{Cl}: 0.48-1.68$; $P=0.74$ ), cardiac death (OR: $0.56,95 \% \mathrm{Cl}: 0.29-1.08 ; P=0.08)$, myocardial infarction (OR: $0.89,95 \% \mathrm{Cl}: 0.62-1.27 ; P=0.53$ ) and stent thrombosis (OR: $0.72,95 \% \mathrm{Cl}: 0.36-1.42 ; P=0.34$ ) were not significantly different.

Conclusion: In patients with coronary bifurcation lesions undergoing $\mathrm{PCl}$, crush stenting technique was associated with significantly lower major adverse cardiac events and repeated revascularization without any change in mortality, myocardial infarction and stent thrombosis when compared to the provisional technique showing a benefit of crush over the provisional stenting technique during $\mathrm{PCl}$.
\end{abstract}

Keywords: Percutaneous coronary intervention, Crush stenting technique, Provisional stenting technique, Major adverse cardiac events, Repeated revascularization, Coronary bifurcation lesions

\footnotetext{
* Correspondence: huangfeng7925@163.com

'Institute of Cardiovascular Diseases and Guangxi Key Laboratory Base of

Precision Medicine in Cardio-cerebrovascular Disease Control and Prevention

and Guangxi Clinical Research Center for Cardio-cerebrovascular Diseases,

the First Affiliated Hospital of Guangxi Medical University, Nanning 530021,

Guangxi, China

Full list of author information is available at the end of the article
}

(c) The Author(s). 2019 Open Access This article is distributed under the terms of the Creative Commons Attribution 4.0 International License (http://creativecommons.org/licenses/by/4.0/), which permits unrestricted use, distribution, and reproduction in any medium, provided you give appropriate credit to the original author(s) and the source, provide a link to the Creative Commons license, and indicate if changes were made. The Creative Commons Public Domain Dedication waiver (http://creativecommons.org/publicdomain/zero/1.0/) applies to the data made available in this article, unless otherwise stated. 


\section{Background}

Percutaneous coronary intervention (PCI) for bifurcation lesions which accounts for approximately 15 to $20 \%$ of patients undergoing this invasive procedure [1] has often been challenging for interventional cardiologists [2]. Even if the estimated annual cost of PCI for bifurcation lesions in the United States is approximately $\$ 4.4$ billion [3], what matters at a later stage is the technique applied in order to prevent future complications [4]. With recent technological progress in interventional cardiology, application of the correct intra-procedural technique is vital to generate beneficial outcomes after coronary angioplasty.

At present, it is still not clear which stenting technique should be applied during PCI with drug eluting stents (DES) for coronary bifurcation lesions. Several trials including the coronary bifurcations: application of the crushing technique using sirolimus-eluting stents) [CACTUS] trial [5], the nordic stent technique study [6], the double kissing crush culotte stenting for the treatment of unprotected distal left main bifurcation lesions (DKCRUSH III) trial [7] have been set up to demonstrate the best intra-operative technique which should be applied for the treatment of bifurcation lesions during PCI.

Nevertheless, the post interventional cardiovascular outcomes associated with different techniques for bifurcation lesions have seldom been systematically studied.

As systematic reviews and meta-analyses might provide practitioners a vehicle to gain access to pre-filtered evidence and considerably save their time and expertise as well as shorten the knowledge gap in the literature to implement evidence-based practice, it was high time to systematically compare stenting techniques for bifurcation lesions.

In this analysis, we aimed to systematically compare the post interventional cardiovascular outcomes observed using the crush versus the provisional stenting techniques for bifurcation lesions.

\section{Methods}

Search databases and search strategies (including search terms)

Following the PRISMA guideline [8], a computerized search was carried out through medical literature analysis and retrieval system online (MEDLINE) and via its interface pubmed, through the biomedical and pharmacological bibliographic database excerpta medica database (EMBASE), through the Cochrane database and through www.ClinicalTrials.gov for English publications comparing crush versus the provisional stenting techniques for coronary bifurcation lesions.

The following search terms were used: "bifurcation lesions and percutaneous coronary intervention", "bifurcation lesions and coronary angioplasty", "bifurcation lesions and revascularization", "crush stenting versus provisional stenting", "crush stenting and percutaneous coronary intervention", "crush stenting and PCI", "crush stenting and provisional stenting and percutaneous coronary intervention".

All the above mentioned databases were searched for relevant publications using these terms. Reference lists were also filtered for any relevant publication.

\section{Criteria for inclusion and exclusion}

Inclusion criteria consisted of:

1. Studies (randomized trials and observational registries) which compared crush versus provisional stenting techniques in patients with coronary bifurcation lesions undergoing PCI;

2. Studies with the above criteria number (1) and additionally reporting adverse cardiovascular outcomes as their main endpoints.

Exclusion criteria consisted of:

1. Studies that compared crush versus culotte stenting techniques;

2. Studies that compared simple versus complex stenting without any specific precision of the type of stenting techniques which were used;

3. Studies that did not report adverse cardiovascular outcomes as their endpoints;

4. Studies that reported data which could not be used in this meta-analysis;

5. Studies that were literature reviews/meta-analyses/ case studies/letters to editors;

6. Duplicated studies.

\section{Types of lesions, outcomes and follow-up time periods} All the participants were patients with coronary bifurcation lesions who were re-vascularized by $\mathrm{PCI}$ as shown in Table 1.

The outcomes which were assessed included:

- Major adverse cardiac events (MACEs) consisting of the total number of death [cardiac and non-cardiac], myocardial infarction and revascularization [target vessel revascularization and/or target lesion revascularization] in combination;

- All-cause mortality;

- Cardiac death;

- Myocardial infarction (MI);

- Target vessel revascularization (TVR);

- Target lesion revascularization (TLR);

- Stent thrombosis (ST). 
Table 1 Types of lesions, outcomes reported and follow-up time periods

\begin{tabular}{|c|c|c|c|}
\hline Studies & Types of lesions + procedure & Outcomes reported & $\begin{array}{l}\text { Follow-up } \\
\text { time periods }\end{array}$ \\
\hline Baystrukov2017 [9] & Bifurcation lesions $+\mathrm{PCl}$ & $\begin{array}{l}\text { Cardiac death, MI, ST, TVR, stroke, } \\
\text { MACE, re-occlusion }\end{array}$ & 12 months \\
\hline CACTUS [5] & True coronary bifurcation $+\mathrm{PCl}$ & MACE, MI, TLR, TVR, death & 1 and 6 months \\
\hline DKCRUSH II [10] & Coronary artery bifurcation lesions $+\mathrm{PCl}$ & $\begin{array}{l}\text { MACE, cardiac death, MI, TLR, } \\
\text { TVR, ST }\end{array}$ & 60 months \\
\hline DKCRUSH V [11] & Left main distal bifurcation lesions $+\mathrm{PCl}$ & $\begin{array}{l}\text { Cardiac death, MI, TLR, ST, MACE, } \\
\text { all-cause mortality, all revascularization }\end{array}$ & 1 and 12 months \\
\hline Galassi2009 [12] & Bifurcation lesions + PCl & $\begin{array}{l}\text { MACE, TVR, TLR, MI, ST, Cardiac } \\
\text { death, all-cause mortality }\end{array}$ & $\begin{array}{l}1 \text { month and } \\
24 \text { months }\end{array}$ \\
\hline Kim2015 [13] & $\begin{array}{l}\text { Coronary artery bifurcation lesions with } \\
\text { or without side branch }+\mathrm{PCl}\end{array}$ & $\begin{array}{l}\text { All-cause mortality, cardiac death, } \\
\text { MI, TVR, TLR, ST, MACE }\end{array}$ & 12 months \\
\hline
\end{tabular}

Abbreviations: $P C l$ percutaneous coronary intervention, $M I$ myocardial infarction, $S T$ stent thrombosis, $T V R$ target vessel revascularization, $T L R$ target lesion revascularization, MACE major adverse cardiac events

A minimum follow-up time period of 6 months and a maximum follow-up time period of 60 months were reported. Therefore, this analysis had a follow-up time period ranging from 6 to 60 months as shown in Table 1 .

\section{Data extraction and quality assessment}

Relevant data including the methodological features, the names of authors, year of publication, time period of patients' enrollment, total number of participants assigned to the crush and provisional stenting groups, the followup time periods, the percentage of patients with diabetes mellitus, hypertension, dyslipidemia, current smoker, the relevant left ventricular ejection fraction, lesion length diameters for the main and side branches, mean age of the participants, the percentage of male and female patients, and the number of events reported for each outcome were independently extracted by two experts.

Any disagreement was carefully discussed and a final decision was made by the corresponding author.

The methodological assessment of the trials was carried out with strict reference to the recommendations by the Cochrane collaboration [14]. Grades were allotted to represent the risk of bias. A grade A denoted a low risk of bias, grade $\mathrm{B}$ denoted a moderate risk and a grade $\mathrm{C}$ denoted a high risk of bias.

\section{Statistical analysis}

Statistical analysis was carried out by the most relevant RevMan 5.3 software. Odds ratios (OR) and 95\% confidence intervals $(\mathrm{CI})$ were generated during statistical analysis to represent the data.

The Q statistic test (where a $P$ value of less or equal to 0.05 was considered statistically significant) and the $I^{2}$ statistic test (a greater value denoting higher heterogeneity and a lower value denoting lower heterogeneity) were used to assess heterogeneity which was often observed in meta-analyses.
Either a fixed effect $\left(\mathrm{I}^{2} \leq 50 \%\right)$ model or a random effect $\left(\mathrm{I}^{2}>50 \%\right)$ model was used during statistical analysis depending upon the value of heterogeneity which was generated.

Sensitivity analysis was also carried out (by exclusion of each study by turn) to observe any significant difference from the main analytical results.

In addition, since this analysis comprised of a very small volume of studies, publication bias was visually assessed through funnel plots.

\section{Ethical approval}

This is an analysis whereby data were collected from other published studies and therefore, ethical or institutional board review approval was not required.

\section{Results}

\section{Search outcomes}

Computerized literature search resulted in a total number of 1654 publications.

Following an initial assessment of the titles and the abstracts, several publications were rejected due to irrelevance and only 82 full text articles were assessed for eligibility.

Further assessment based on the inclusion and exclusion criteria resulted in another set of elimination of the full text articles:

- One (1) meta-analysis;

- Three (3) letters to editors;

- Five (5) case studies;

- Three (3) literature reviews;

- Trials reporting crush versus culotte stenting (6);

- Trials reporting provisional versus routine T stenting (3);

- Trials reporting simple versus complex stenting (3);

- Trials reporting tryton stent versus provisional stenting (1);

- Duplicated studies (51). 
Finally only 6 studies [5, 9-13] were selected for this analysis as shown in Fig. 1.

\section{Main features of the relevant studies}

Six studies with a total number of 2220 participants (1085 participants were assigned to the crush stenting technique and 1135 participants were assigned to the provisional stenting technique) were included in this analysis. The time period of patients' enrollment was between years 2004 and 2016 as shown in Table 2.

Following the methodological assessment, four trials were graded into the "A category" implying a low risk of bias, and one trial was graded into the "B category" indicating a low to moderate risk of bias as shown in Table 2.

The baseline features of the participants have been listed in Table 3. Mean age was reported in years, and the other features were reported in percentage or millimeters.

\section{Main results of this analysis}

During a follow-up time period from six months to sixty months, crush stenting technique was associated with significantly lower major adverse cardiac events (OR: 0.73, 95\% CI: 0.59-0.91; $P=0.005$ ), TVR (OR: 0.62, 95\% CI: $0.43-0.89 ; P=0.01$ ) and TLR (OR: 0.62 , 95\% CI: $0.45-$
$0.85 ; P=0.003)$ as compared to the provisional stenting technique for coronary bifurcation lesions (Fig. 2).

However, all-cause mortality (OR: 0.90, 95\% CI: $0.48-1.68 ; P=0.74$ ), cardiac death (OR: $0.56,95 \% \mathrm{CI}$ : 0.29-1.08; $P=0.08$ ), MI (OR: 0.89, 95\% CI: 0.62-1.27; $P=0.53$ ) and stent thrombosis (OR: $0.72,95 \% \mathrm{CI}$ : $0.36-1.42 ; P=0.34$ ) were not significantly different between the crush and the provisional stenting technique as shown in Fig. 3.

A summarized version of this main result has been given in Table 4.

Another separate analysis was carried out at 1 year follow-up. All the studies which reported outcomes at 12 months were included in this new analysis. Major adverse cardiac events (OR: 0.67, 95\% CI: 0.48-0.96; $P=0.03$ ), TVR (OR: 0.41, 95\% CI: $0.21-0.78 ; P=0.006$ ) and TLR (OR: $0.48,95 \%$ CI: $0.24-0.95 ; P=0.04$ ) still significantly favored the crush stenting technique as shown in Fig. 4. At 1 year follow-up, all-cause mortality (OR: 1.43, 95\% CI: $0.54-3.80 ; P=0.47$ ), cardiac death (OR: 0.42 , 95\% CI: $0.11-1.64 ; P=0.21$ ), MI (OR: $0.80,95 \%$ CI: $0.21-$ 3.03; $P=0.74$ ) and stent thrombosis (OR: $0.97,95 \% \mathrm{CI}$ : $0.08-12.28 ; P=0.98$ ) were similarly manifested between the crush versus the provisional stenting technique as shown in Figs. 4 and 5.

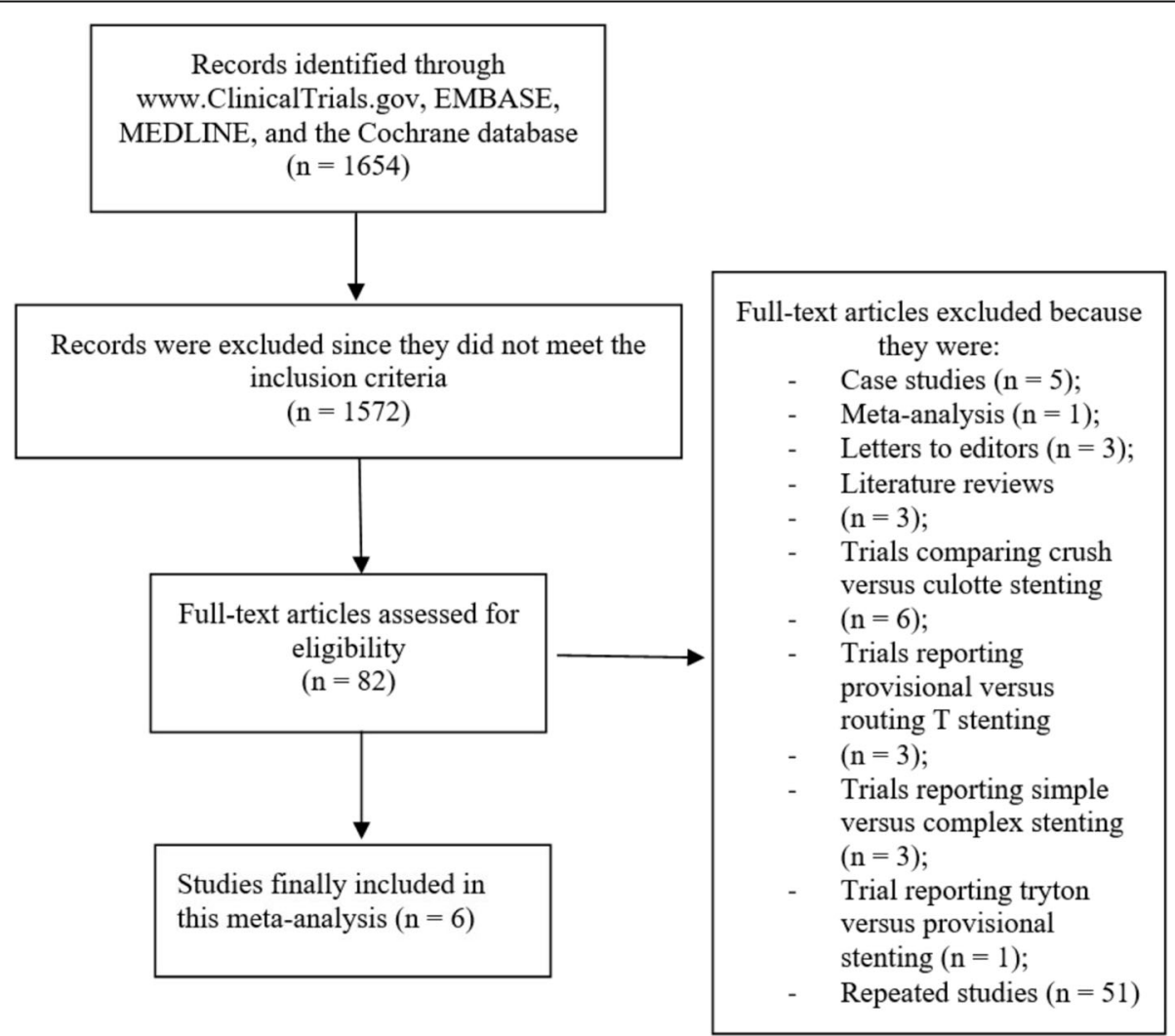

Fig. 1 Flow diagram representing the study selection for crush versus provisional stenting technique during percutaneous coronary intervention for coronary bifurcation lesions 
Table 2 Main features of the studies

\begin{tabular}{|c|c|c|c|c|c|}
\hline Studies & $\begin{array}{l}\text { No of participants assigned } \\
\text { to crush technique } \\
\text { (n) }\end{array}$ & $\begin{array}{l}\text { No of participants assigned } \\
\text { to provisional stenting technique } \\
\text { (n) }\end{array}$ & $\begin{array}{l}\text { Time period of } \\
\text { patients' enrollment } \\
\text { (years) }\end{array}$ & $\begin{array}{l}\text { Type of } \\
\text { study }\end{array}$ & $\begin{array}{l}\text { Bias risk } \\
\text { grade }\end{array}$ \\
\hline Baystrukov2017 & 73 & 73 & $2011-2013$ & $\mathrm{RCT}$ & B \\
\hline CACTUS & 177 & 173 & 2004-2007 & $\mathrm{RCT}$ & A \\
\hline DKCRUSH II & 183 & 183 & 2007-2009 & $\mathrm{RCT}$ & A \\
\hline DKCRUSH V & 240 & 242 & 2011-2016 & $\mathrm{RCT}$ & A \\
\hline Galassi2009 & 199 & 258 & 2004-2006 & OS & - \\
\hline Kim2015 & 213 & 206 & 2008-2015 & $\mathrm{RCT}$ & A \\
\hline Total no of patients (n) & 1085 & 1135 & & & \\
\hline
\end{tabular}

Abbreviations: $R C T$ randomized controlled trials, OS observational studies

\section{Sensitivity analyses and publication bias}

When an analysis was carried out without study Baystrukov2017, the results for important outcomes such as major adverse cardiac events (OR: 0.77, 95\% CI: $0.61-0.97 ; P=0.02$ ), cardiac death (OR: $0.57,95 \% \mathrm{CI}$ : $0.29-1.12 ; P=0.10$ ), MI (OR: $0.86,95 \% \mathrm{CI}: 0.60-1.23$; $P=0.41$ ) and stent thrombosis (OR: 0.61, 95\% CI: $0.29-1.26 ; \quad P=0.18)$ were not significantly different when compared to the main results of this analysis.

When study Galassi2009 was excluded, there was still no significant change in the results with reference to the main analysis: major adverse cardiac events (OR: 0.73, 95\% CI: 0.57-0.95; P =0.02), all-cause mortality (OR: $1.23,95 \% \mathrm{CI}: 0.49-3.07 ; P=0.65$ ), cardiac death (OR: 0.53, 95\% CI: 0.21-1.34; P =0.18), MI (OR: 1.01, 95\% CI: 0.69-1.48; $P=0.95$ ), TVR (OR: 0.60, 95\% CI: $0.41-0.87 ; P=0.007$ ), TLR (OR: $0.60,95 \% \mathrm{CI}$ : $0.40-0.89 ; P=0.01$ ) and stent thrombosis (OR: 0.71, 95\% CI: 0.31-1.61; P = 0.41).

Consistent results were maintained throughout when the other remaining studies were excluded.
Publication bias, which was visually assessed through the funnel plots (Figs. 6 and 7), did not significantly vary (low evidence of publication bias) among all the studies that assessed the cardiovascular outcomes observed with the two different stenting techniques for coronary bifurcation lesions.

\section{Discussion}

According to this current analysis, crush stenting technique was associated with significantly lower major adverse cardiac events, and significantly lower repeated revascularization rates compared to the provisional stenting technique for bifurcation lesions whereas mortality, MI and stent thrombosis were similarly manifested following this interventional procedure.

Similarly, results of the 3 year follow-up of the DKCRUSH-III study showed crush stenting to be associated with a significantly lower major adverse cardiac events as compared to the culotte stenting technique for unprotected left main distal bifurcation lesions [7]. And it was shown that major adverse cardiac events

Table 3 Baseline characteristics of the participants and lesions

\begin{tabular}{|c|c|c|c|c|c|c|}
\hline Studies & Baystrukov2017 & CACTUS & DKCRUSH II & DKCRUSH V & Galassi2009 & Kim2015 \\
\hline Features & CT/PS & $C T / P S$ & CT/PS & CT/PS & CT/PS & $C T / P S$ \\
\hline Mean Age (years) & $57.3 / 58.5$ & $65.0 / 67.0$ & $63.9 / 64.7$ & $65.0 / 64.0$ & $62.2 / 64.5$ & $60.9 / 61.1$ \\
\hline Males (\%) & 75.3/78.1 & $80.2 / 76.3$ & 78.8/75.8 & $82.9 / 77.7$ & $83.9 / 73.4$ & $75.1 / 75.2$ \\
\hline Hypertension (\%) & $91.8 / 91.8$ & 70.6/79.8 & $65.2 / 60.9$ & $72.9 / 64.5$ & $52.3 / 68.2$ & $55.4 / 55.3$ \\
\hline Diabetes mellitus (\%) & $24.7 / 24.7$ & $23.7 / 22.0$ & 19.6/23.1 & $28.8 / 25.6$ & $30.7 / 33.5$ & 25.8/29.1 \\
\hline Dyslipidemia (\%) & $63.0 / 60.3$ & $63.8 / 70.5$ & $33.7 / 29.1$ & $47.5 / 47.5$ & $60.8 / 57.3$ & $62.0 / 57.3$ \\
\hline Current smoker (\%) & $32.9 / 35.6$ & $20.3 / 16.8$ & - & $34.2 / 32.2$ & $63.3 / 52.2$ & $25.4 / 32.5$ \\
\hline LVEF (\%) & $58.4 / 55.3$ & $55.0 / 57.0$ & - & $59.0 / 60.0$ & $50.9 / 49.6$ & $60.4 / 59.5$ \\
\hline True BFL & $67.1 / 64.4$ & $100 / 100$ & - & - & - & - \\
\hline SB diameter (mm) & $2.30 / 2.40$ & - & - & - & $2.55 / 2.54$ & - \\
\hline Previous attempt (\%) & $2.70 / 8.20$ & - & - & - & - & - \\
\hline Lesion length: main branch (mm) & - & - & $25.8 / 25.8$ & $27.9 / 28.8$ & - & $28.9 / 27.8$ \\
\hline Lesion length: side branch (mm) & - & - & $15.3 / 14.6$ & $21.0 / 21.3$ & - & $10.3 / 8.30$ \\
\hline
\end{tabular}

Abbreviations: $C T$ crush technique, PS provisional stenting, SB side branch, LVEF left ventricular ejection fraction, $B F L$ bifurcation lesion, $m m$ millimeters 


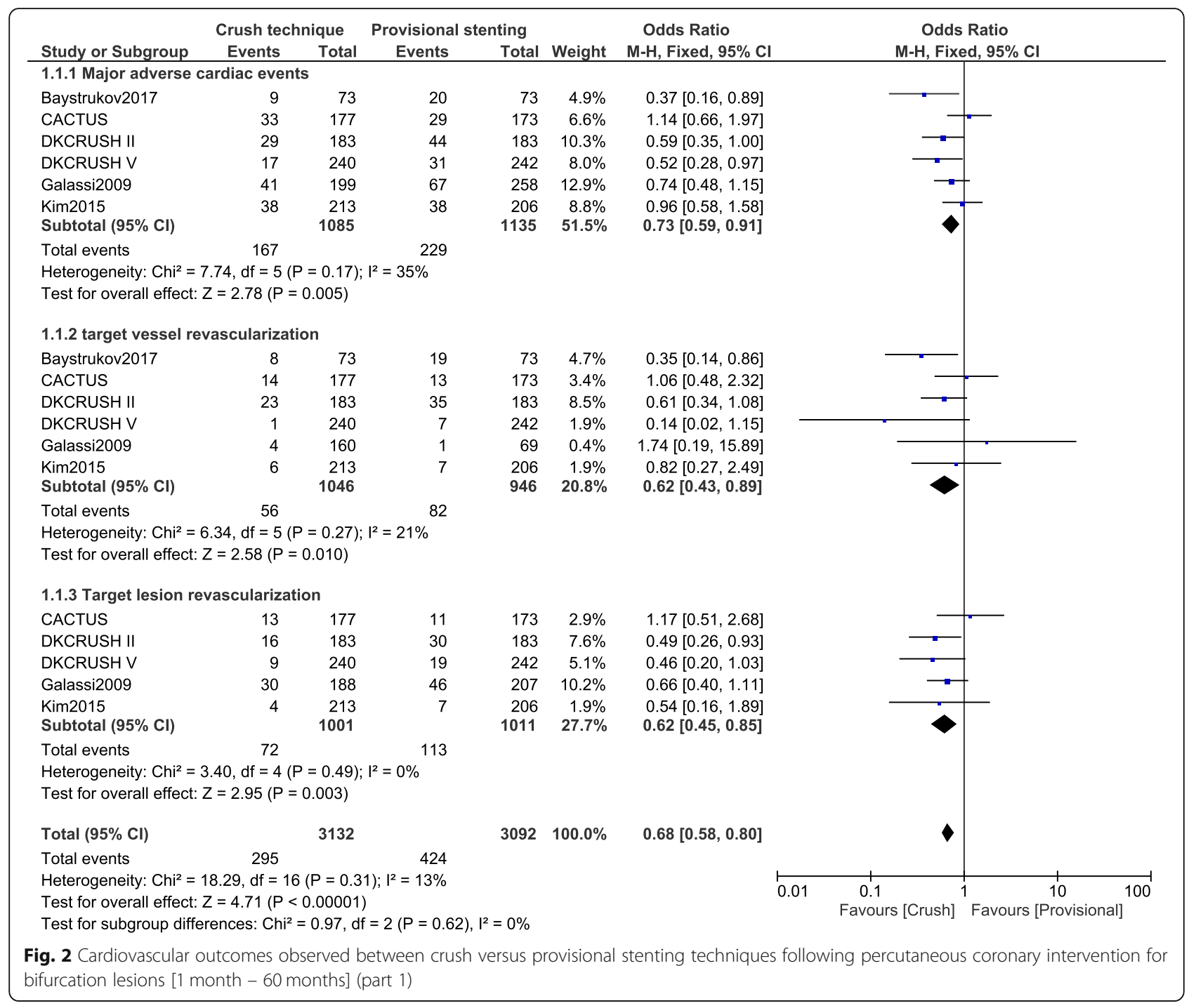

significantly increased with the culotte technique because of an increased rate of target vessel revascularization. This current analysis reported a significantly lower TVR and TLR with significantly reduced major adverse cardiac event associated with the crush stenting technique following the invasive procedure.

Results from the five year follow-up of the DKCRUSH-II (randomized study on double kissing crush technique versus provisional stenting technique for coronary artery bifurcation lesions) study showed crush stenting technique to be associated with a decreased rate of target lesion revascularization indicating an advantage of this stenting technique [10]. Our current analysis also showed the same result in terms of target vessel and target lesion revascularizations further confirming the results of the DKCRUSH-II trial.

In the CACTUS trial [5], the authors found that if stenosis was present in both branches of the bifurcation lesion, a provisional stenting of the main branch would be effective, but would also require the implantation of another stent on the side branch in one third of the number of patients. Major adverse cardiac events were similarly manifested in the crush stenting (15.8\%) and the provisional stenting (15\%) group. However, in this current analysis, which also included the CACTUS trial along with other relevant studies, major adverse cardiac events were significantly in favor of the crush stenting. The reason for such a result might have been the impact of revascularization (more number of events) as a major component of major adverse cardiac events.

Also, the DEFINITION Study (definitions and impact of complex bifurcation lesions on clinical outcomes after percutaneous coronary intervention using drug eluting stents) which compared provisional stenting and 2-stent strategies in patients with simple and complex bifurcation lesions showed both techniques to be almost similar in terms of major adverse cardiac events at 1 year follow-up [15]. 


\begin{tabular}{|c|c|c|c|c|c|c|c|c|c|}
\hline \multirow[b]{2}{*}{ Study or Subgroup } & \multicolumn{2}{|c|}{ Crush technique } & \multicolumn{2}{|c|}{ Provisional stenting } & \multirow[b]{2}{*}{ Weight } & \multirow{2}{*}{$\begin{array}{l}\text { Odds Ratio } \\
\text { M-H, Fixed, } 95 \% \mathrm{Cl}\end{array}$} & \multirow{2}{*}{\multicolumn{3}{|c|}{$\begin{array}{l}\text { Odds Ratio } \\
\text { M-H, Fixed, } 95 \% \mathrm{Cl}\end{array}$}} \\
\hline & Events & Total & Events & Total & & & & & \\
\hline \multicolumn{10}{|c|}{ 1.1.1 All-cause mortality } \\
\hline CACTUS & 0 & 177 & 1 & 173 & $1.2 \%$ & $0.32[0.01,8.01]$ & & & \\
\hline DKCRUSH V & 7 & 240 & 5 & 242 & $3.7 \%$ & $1.42[0.45,4.55]$ & & & \\
\hline Galassi2009 & 8 & 199 & 15 & 258 & $9.6 \%$ & $0.68[0.28,1.63]$ & & & - \\
\hline $\begin{array}{l}\text { Kim2015 } \\
\text { Subtotal }(95 \% \mathrm{Cl})\end{array}$ & 3 & $\begin{array}{l}213 \\
829\end{array}$ & 2 & $\begin{array}{l}206 \\
879\end{array}$ & $\begin{array}{r}1.5 \% \\
16.0 \%\end{array}$ & $\begin{array}{c}1.46[0.24,8.81] \\
0.90[0.48,1.68]\end{array}$ & & & \\
\hline Total events & 18 & & 23 & & & & & & \\
\hline \multicolumn{10}{|c|}{ Heterogeneity: $\mathrm{Chi}^{2}=1.66, \mathrm{df}=3(\mathrm{P}=0.65) ; \mathrm{I}^{2}=0 \%$} \\
\hline \multicolumn{10}{|l|}{ 1.1.2 Cardiac death } \\
\hline Baystrukov2017 & 0 & 73 & 1 & 73 & $1.1 \%$ & $0.33[0.01,8.20]$ & & & \\
\hline DKCRUSH II & 4 & 183 & 6 & 183 & $4.5 \%$ & $0.66[0.18,2.38]$ & & & \\
\hline DKCRUSH V & 0 & 240 & 4 & 242 & $3.4 \%$ & $0.11[0.01,2.06]$ & & & \\
\hline Galassi2009 & 7 & 199 & 15 & 258 & $9.7 \%$ & $0.59[0.24,1.48]$ & & & - \\
\hline $\begin{array}{l}\text { Kim2015 } \\
\text { Subtotal }(95 \% \mathrm{Cl})\end{array}$ & 2 & $\begin{array}{l}213 \\
908\end{array}$ & 1 & $\begin{array}{l}206 \\
962\end{array}$ & $\begin{array}{r}0.8 \% \\
19.5 \%\end{array}$ & $\begin{array}{r}1.94[0.17,21.59] \\
0.56[0.29,1.08]\end{array}$ & & & \\
\hline Total events & 13 & & 27 & & & & & & \\
\hline \multicolumn{10}{|c|}{ Heterogeneity: $\mathrm{Chi}^{2}=2.39, \mathrm{df}=4(\mathrm{P}=0.66) ; \mathrm{I}^{2}=0 \%$} \\
\hline \multicolumn{10}{|c|}{ Test for overall effect: $Z=1.74(P=0.08)$} \\
\hline \multicolumn{10}{|c|}{ 1.1.3 Myocardial infarction } \\
\hline Baystrukov2017 & 3 & 73 & 1 & 73 & $0.7 \%$ & $3.09[0.31,30.38]$ & & & \\
\hline CACTUS & 19 & 177 & 15 & 173 & $10.4 \%$ & $1.27[0.62,2.58]$ & & & \\
\hline DKCRUSH II & 7 & 183 & 6 & 183 & $4.4 \%$ & $1.17[0.39,3.56]$ & & & \\
\hline DKCRUSH V & 1 & 240 & 7 & 242 & $5.3 \%$ & $0.14[0.02,1.15]$ & & & \\
\hline Galassi2009 & 4 & 199 & 14 & 258 & $9.1 \%$ & $0.36[0.12,1.10]$ & & & \\
\hline Kim2015 & 30 & 213 & 29 & 206 & $19.4 \%$ & $1.00[0.58,1.74]$ & & & \\
\hline Subtotal $(95 \% \mathrm{Cl})$ & & 1085 & & 1135 & $49.4 \%$ & $0.89[0.62,1.27]$ & & & \\
\hline Total events & 64 & & 72 & & & & & & \\
\hline \multicolumn{10}{|c|}{ Heterogeneity: $\mathrm{Chi}^{2}=7.96, \mathrm{df}=5(P=0.16) ; \mathrm{I}^{2}=37 \%$} \\
\hline \multicolumn{10}{|c|}{ Test for overall effect: $Z=0.63(P=0.53)$} \\
\hline \multicolumn{10}{|c|}{ 1.1.4 Stent thrombosis } \\
\hline Baystrukov2017 & 2 & 73 & 0 & 73 & $0.4 \%$ & $5.14[0.24,108.94]$ & & & \\
\hline DKCRUSH II & 5 & 183 & 5 & 183 & $3.7 \%$ & $1.00[0.28,3.51]$ & & & \\
\hline DKCRUSH V & 1 & 240 & 8 & 242 & $6.1 \%$ & $0.12[0.02,0.99]$ & & & \\
\hline Galassi2009 & 4 & 199 & 7 & 258 & $4.6 \%$ & $0.74[0.21,2.55]$ & & & \\
\hline $\begin{array}{l}\text { Kim2015 } \\
\text { Subtotal (95\% Cl) }\end{array}$ & 1 & $\begin{array}{l}213 \\
908\end{array}$ & 0 & $\begin{array}{l}206 \\
962\end{array}$ & $\begin{array}{r}0.4 \% \\
15.1 \%\end{array}$ & $\begin{array}{r}2.92[0.12,71.97] \\
0.72[0.36,1.42]\end{array}$ & & & \\
\hline Total events & 13 & & 20 & & & & & & \\
\hline \multirow{2}{*}{\multicolumn{10}{|c|}{$\begin{array}{l}\text { Heterogeneity: } \mathrm{Chi}^{2}=5.36, \mathrm{df}=4(P=0.25) ; I^{2}=25 \% \\
\text { Test for overall effect: } Z=0.95(P=0.34)\end{array}$}} \\
\hline & & & & & & & & & \\
\hline Total $(95 \% \mathrm{Cl})$ & & 3730 & & 3938 & $100.0 \%$ & $0.80[0.62,1.04]$ & & & \\
\hline Total events & 108 & & 142 & & & & & & \\
\hline \multirow{3}{*}{\multicolumn{7}{|c|}{$\begin{array}{l}\text { Heterogeneity: } \mathrm{Chi}^{2}=18.80, \mathrm{df}=19(P=0.47) ; \mathrm{I}^{2}=0 \% \\
\text { Test for overall effect: } Z=1.68(P=0.09) \\
\text { Test for subgroup differences: } \mathrm{Chi}^{2}=1.73, \mathrm{df}=3(P=0.63), \mathrm{I}^{2}=0 \%\end{array}$}} & & 0.1 & 10 \\
\hline & & & & & & & & ${ }_{\text {Favours [Crush] }}^{0.1}$ & Favours [Provisional] \\
\hline & & & & & & & & & \\
\hline \multicolumn{10}{|c|}{$\begin{array}{l}\text { Fig. } 3 \text { Cardiovascular outcomes observed between crush versus provisional stenting techniques following percutaneous coronary intervention for } \\
\text { bifurcation lesions [1 month to } 60 \text { months] (part 2) }\end{array}$} \\
\hline
\end{tabular}

Table 4 Results of this analysis

\begin{tabular}{|c|c|c|c|c|}
\hline Outcomes assessed & Total no of studies involved (n) & OR with 95\% Cl & $P$ value & $1^{2}$ value $(\%)$ \\
\hline Major adverse cardiac events & 6 & $0.73[0.59-0.91]$ & 0.005 & 35 \\
\hline All-cause mortality & 4 & $0.90[0.48-1.68]$ & 0.74 & 0 \\
\hline Cardiac death & 5 & $0.56[0.29-1.08]$ & 0.08 & 0 \\
\hline Myocardial infarction & 6 & $0.89[0.62-1.27]$ & 0.53 & 37 \\
\hline Target vessel revascularization & 6 & $0.62[0.43-0.89]$ & 0.01 & 21 \\
\hline Target lesion revascularization & 5 & $0.62[0.45-0.85]$ & 0.003 & 0 \\
\hline Stent thrombosis & 5 & $0.72[0.36-1.42]$ & 0.34 & 25 \\
\hline
\end{tabular}

Abbreviations: $\mathrm{OR}$ odds ratios, $\mathrm{Cl}$ confidence intervals 


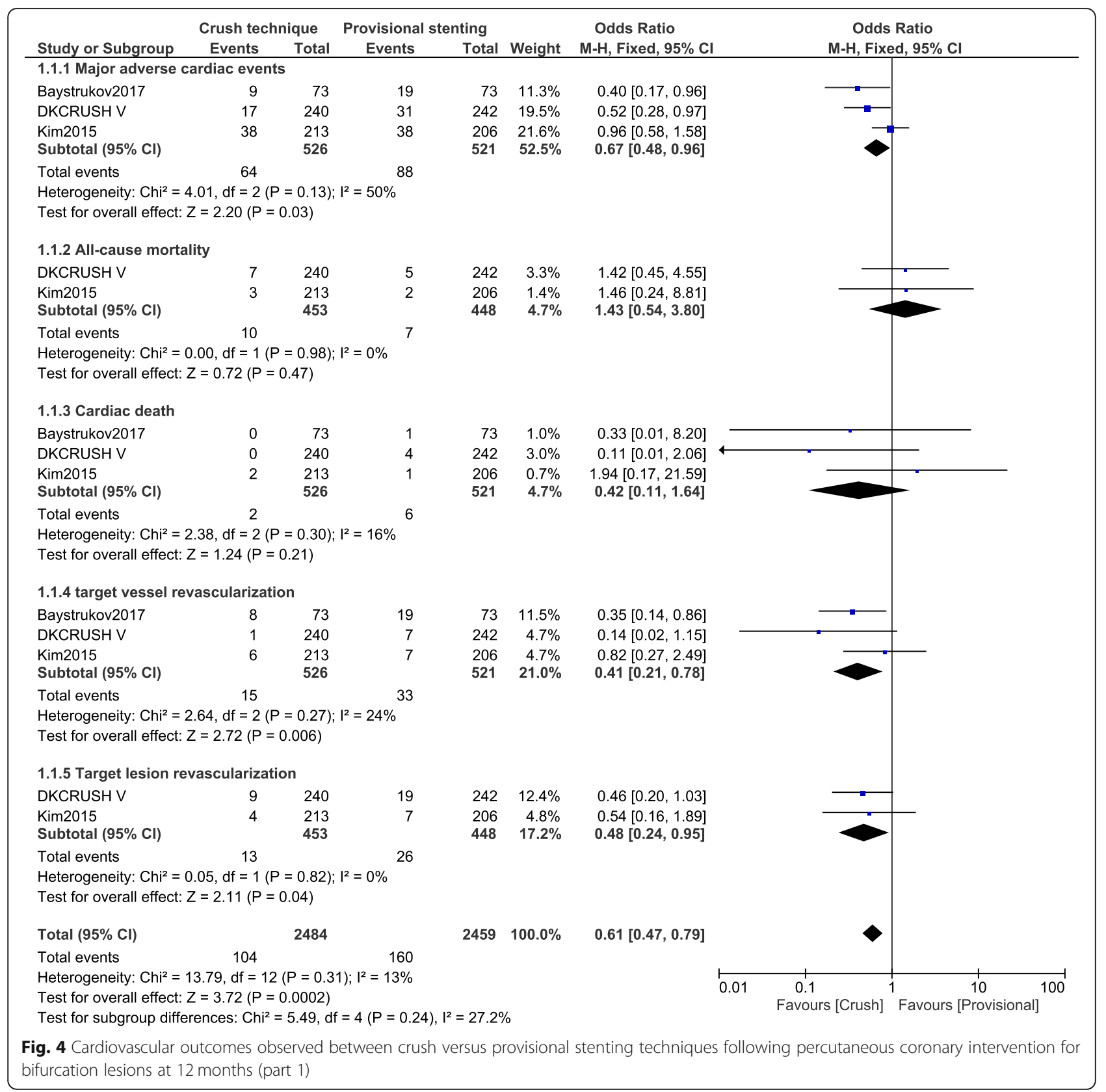

Nevertheless, different from this current analysis, the TRYTON (prospective, single blind, randomized controlled study to evaluate the safety and effectiveness of the tryton side branch stent used with DES in treatment of de novo bifurcation lesions in the main branch and side branch in native coronaries) bifurcation Trial which randomly assigned 704 patients with bifurcation coronary lesions at 58 centers showed provisional stenting to remain the preferred strategy for non-left main true bifurcation lesions [16]. Also, a 5-year survival from patient-level pooled analysis of the nordic bifurcation study and the British bifurcation coronary study showed a provisional single stent approach to be associated with lower long term mortality in comparison to the dual stenting technique [17].

Few studies have also shown double stenting to be associated with higher major adverse cardiac events. Explanations might be related to the complexity of the appropriate lesions. More complicated coronary lesions might introduce higher complications during intra-procedural double stenting. The corresponding anatomical structure, torturous proximal, with moderate to severe calcification might further contribute to unwanted cardiac events post procedure [15]. Moreover, narrow 


\begin{tabular}{|c|c|c|c|c|c|c|c|c|c|}
\hline \multirow[b]{2}{*}{ Study or Subgroup } & \multicolumn{2}{|c|}{ Crush technique } & \multicolumn{2}{|c|}{ Provisional stenting } & \multirow[b]{2}{*}{ Weight } & \multirow{2}{*}{$\begin{array}{l}\text { Odds Ratio } \\
\text { M-H, Random, } 95 \% \mathrm{Cl}\end{array}$} & \multirow{2}{*}{\multicolumn{3}{|c|}{$\begin{array}{c}\text { Odds Ratio } \\
\text { M-H, Random, } 95 \% \mathrm{Cl}\end{array}$}} \\
\hline & Events & Total & Events & Total & & & & & \\
\hline \multicolumn{10}{|c|}{ 1.1.1 Myocardial infarction } \\
\hline Baystrukov2017 & 3 & 73 & 1 & 73 & $14.4 \%$ & $3.09[0.31,30.38]$ & & & \\
\hline DKCRUSH V & 1 & 240 & 7 & 242 & $15.9 \%$ & $0.14[0.02,1.15]$ & & & \\
\hline $\begin{array}{l}\text { Kim2015 } \\
\text { Subtotal (95\% Cl) }\end{array}$ & 30 & $\begin{array}{l}213 \\
526\end{array}$ & 29 & $\begin{array}{l}206 \\
\mathbf{5 2 1}\end{array}$ & $\begin{array}{l}34.9 \% \\
65.2 \%\end{array}$ & $\begin{array}{l}1.00[0.58,1.74] \\
0.80[0.21,3.03]\end{array}$ & & & \\
\hline Total events & 34 & & 37 & & & & & & \\
\hline \multicolumn{10}{|c|}{ Heterogeneity: $\mathrm{Tau}^{2}=0.78 ; \mathrm{Chi}^{2}=4.29, \mathrm{df}=2(\mathrm{P}=0.12) ; \mathrm{I}^{2}=53 \%$} \\
\hline \multicolumn{10}{|c|}{ 1.1.2 Stent thrombosis } \\
\hline Baystrukov2017 & 2 & 73 & 0 & 73 & $9.7 \%$ & $5.14[0.24,108.94]$ & & & \\
\hline DKCRUSH V & 1 & 240 & 8 & 242 & $16.1 \%$ & $0.12[0.02,0.99]$ & & & \\
\hline $\begin{array}{l}\text { Kim2015 } \\
\text { Subtotal (95\% Cl) }\end{array}$ & 1 & $\begin{array}{l}213 \\
526\end{array}$ & 0 & $\begin{array}{l}206 \\
521\end{array}$ & $\begin{array}{r}9.0 \% \\
34.8 \%\end{array}$ & $\begin{array}{c}2.92[0.12,71.97] \\
0.97[0.08,12.28]\end{array}$ & & & \\
\hline Total events & 4 & & 8 & & & & & & \\
\hline \multicolumn{10}{|c|}{$\begin{array}{l}\text { Heterogeneity: } \mathrm{Tau}^{2}=3.04 ; \mathrm{Chi}^{2}=5.09, \mathrm{df}=2(P=0.08) ; \mathrm{I}^{2}=61 \% \\
\text { Test for overall effect: } Z=0.02(P=0.98)\end{array}$} \\
\hline Total $(95 \% \mathrm{Cl})$ & & 1052 & & 1042 & $100.0 \%$ & $0.79[0.26,2.38]$ & & & \\
\hline Total events & 38 & & 45 & & & & & & \\
\hline $\begin{array}{l}\text { Heterogeneity: } \mathrm{Tau}^{2} \\
\text { Test for overall effect } \\
\text { Test for subgroup diff }\end{array}$ & $\begin{array}{l}\text {. } 82 ; \mathrm{Chi}^{2}= \\
=0.42(\mathrm{P} \\
\text { ences: } \mathrm{Chi}\end{array}$ & $\begin{array}{l}71, \mathrm{df}= \\
.68) \\
0.02, \mathrm{df}\end{array}$ & $\begin{array}{l}5(P=0.08) ; \\
f=1(P=0.8\end{array}$ & $\begin{array}{l}49 \% \\
=0 \%\end{array}$ & & & 0.01 & $\begin{array}{cc}0.1 \\
\text { Favours [Crush] }\end{array}$ & $1 \begin{array}{cc}10 & 100 \\
\text { Favours [Provisional] }\end{array}$ \\
\hline
\end{tabular}

bifurcation angle of ostial side branch might be rather challenging and might thus increase the changes for future stent thrombosis [18].

Other stenting techniques were associated with unwanted outcomes. Results from the British bifurcation coronary study: old, new, and evolving strategies showed that when coronary bifurcation lesions were treated, significantly increased major adverse cardiac events were observed with the systemic 2-stent technique and the reason was mainly due to MI reported during the procedure [19]. In addition, insight from in vitro experiments and micro-computed tomography showed crush technique to be associated with higher risks of mal-apposition than culotte or the T technique [20].

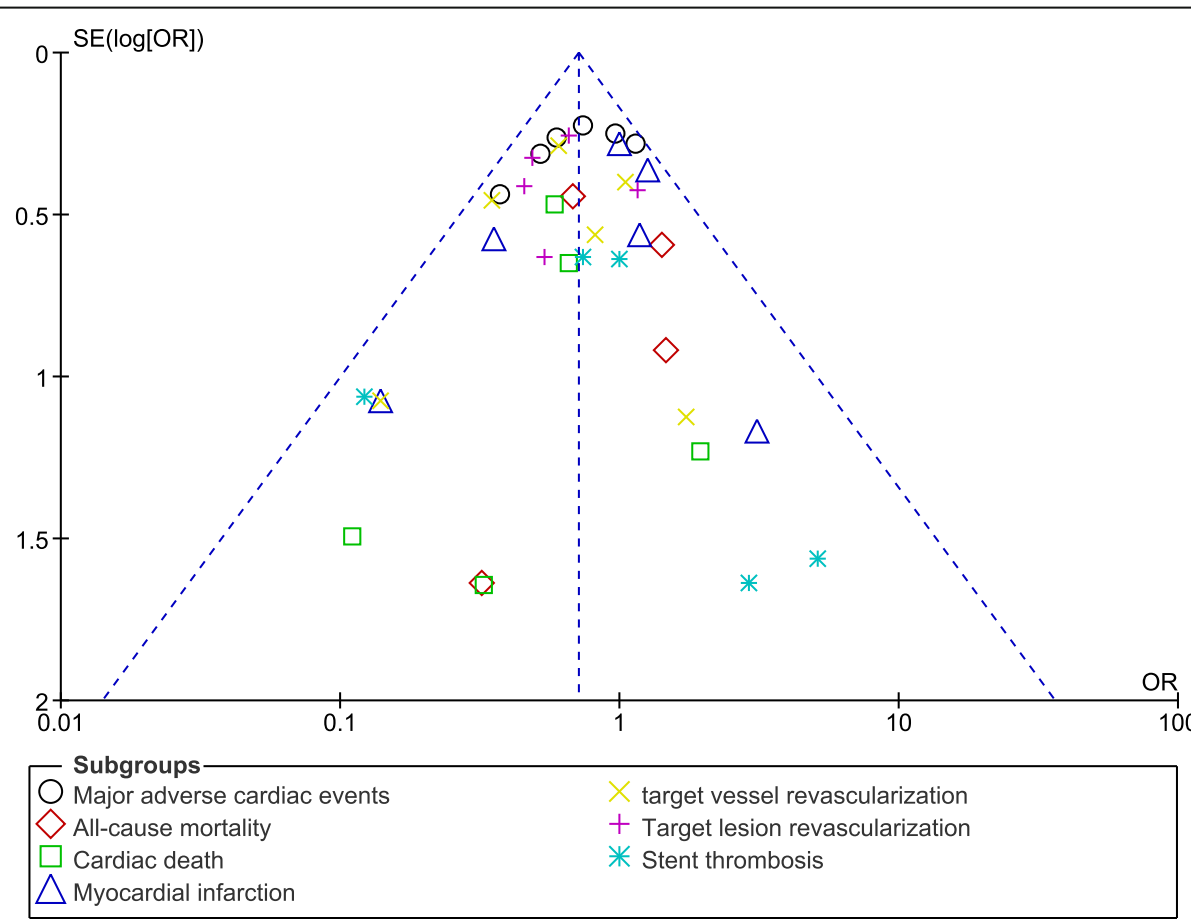

Fig. 6 Funnel plot showing publication bias (A) 


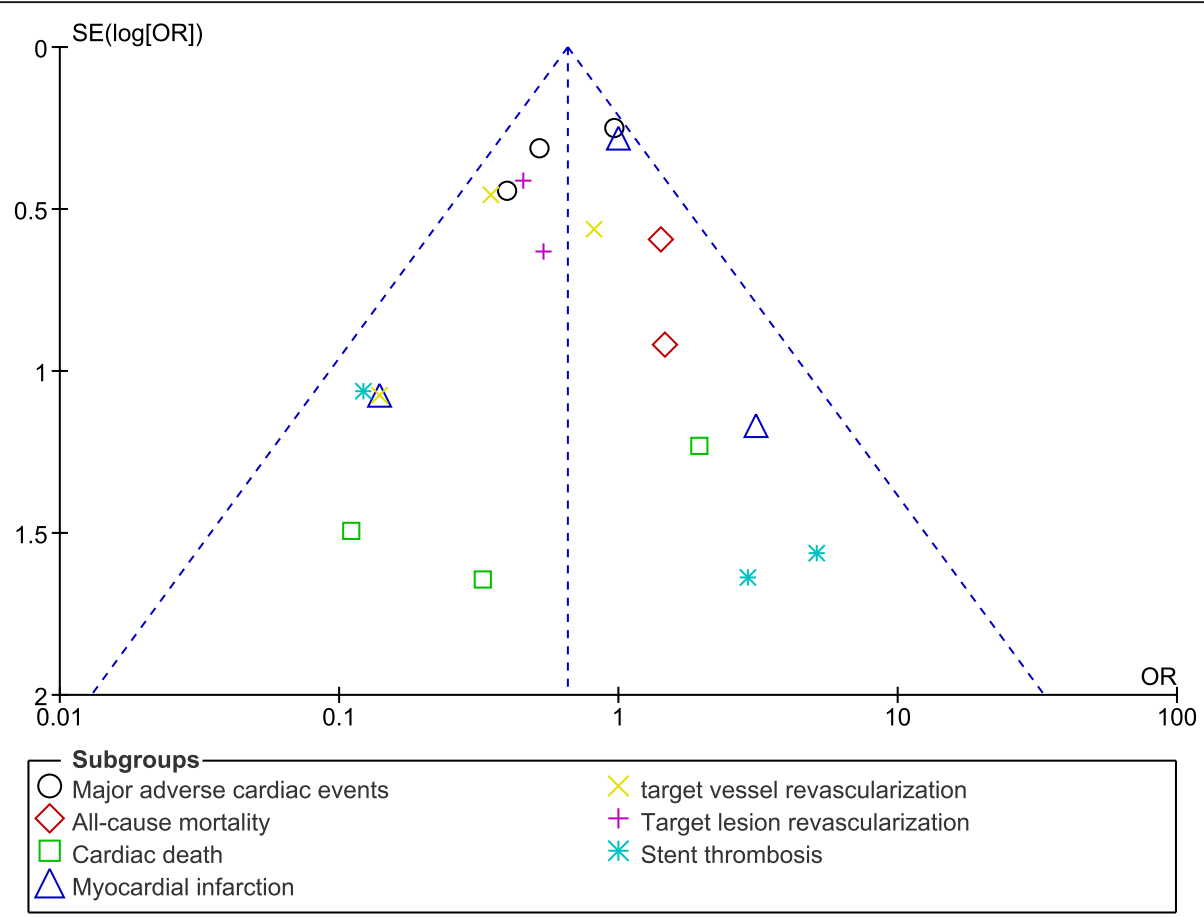

Fig. 7 Funnel plot showing publication bias (B)

This systematic review and meta-analysis has briefly shown the post percutaneous coronary interventional outcomes observed in patients who were assigned to the crush versus the provisional intra-procedural stenting technique for bifurcation lesions. This evidence based analysis might be of some importance to interventional cardiologists.

\section{Limitations}

This current meta-analysis has the following limitations: In general, the total number of participants who were assigned to the crush stenting versus the provisional stenting technique was limited. Therefore, our first limitation would be the insufficient total number of participants in comparison to other meta-analyses [21, 22]. However, the total number of participants were at least enough to reach a fair conclusion. Another limitation of this analysis would be the fact that antiplatelet therapies and other cardiac medications were not taken into consideration. In addition, the duration of antiplatelet treatment was also completely ignored, and this might have influenced the results. In this analysis, five studies were randomized controlled trials and one study was an observational study. As data extracted from observational studies were not as efficient in comparison to data which were extracted from randomized controlled trials, data from the observational cohort might have introduced heterogeneity and contributed to bias. Nevertheless, one study would not affect the final results as such. Also, the DEFINITION and the TRYTON studies could not be included in this analysis since they did not satisfy our inclusion criteria. Furthermore, in different studies, different types of drug eluting stents were used, and this could have had an impact on this analysis but we could not rectify this issue since the comparison of the two stenting techniques were not classified according to drug eluting stents. Also, even if a subgroup analysis based on left main versus non-left main bifurcation for PCI would have been of great interest, due to our limited data which did not sufficiently compare these two features, a comparison was not possible.

\section{Conclusion}

In patients with coronary bifurcation lesions undergoing PCI, crush stenting technique was associated with significantly lower major adverse cardiac events and repeated revascularization without any change in mortality, myocardial infarction and stent thrombosis when compared to the provisional technique showing a benefit of crush stenting over the provisional stenting technique during PCI.

\section{Abbreviations}

CBL: Coronary bifurcation lesions; MACEs: Major adverse cardiac events; OR: Odds ratios; PCl: Percutaneous coronary intervention

Acknowledgements Not applicable. 


\section{Funding}

No external funding was used in the preparation of this manuscript. This research was supported by National Natural Science Foundation of China (No. 81560046, 81760057) and Guangxi Natural Science Foundation (No. 2016GXNSFAA380002)

\section{Availability of data and materials}

All data and materials used in this research are freely available in electronic databases. References have been provided.

\section{Authors' contributions}

FH and ZL were responsible for the conception and design, acquisition of data, analysis and interpretation of data, drafting the initial manuscript and revising it critically for important intellectual content. FH wrote this manuscript. All authors read and approved the final manuscript.

\section{Authors' information}

Dr. Feng Huang is the first author. Institute of Cardiovascular Diseases and Guangxi Key Laboratory Base of Precision Medicine in Cardio-cerebrovascular Disease Control and Prevention and Guangxi Clinical Research Center for Cardio-cerebrovascular Diseases, the First Affiliated Hospital of Guangxi Medical University, Nanning 530021, Guangxi, China.

\section{Ethics approval and consent to participate}

Ethical approval was not applicable for this systematic review and metaanalysis.

\section{Consent for publication}

$$
\text { Not applicable. }
$$

\section{Competing interests}

Dr. Feng Huang and Dr. Zu-chun Luo declare that they have no potential conflicts of interest that might be relevant to the contents of this manuscript.

\section{Publisher's Note}

Springer Nature remains neutral with regard to jurisdictional claims in published maps and institutional affiliations.

\section{Author details}

'Institute of Cardiovascular Diseases and Guangxi Key Laboratory Base of Precision Medicine in Cardio-cerebrovascular Disease Control and Prevention and Guangxi Clinical Research Center for Cardio-cerebrovascular Diseases, the First Affiliated Hospital of Guangxi Medical University, Nanning 530021, Guangxi, China. ${ }^{2}$ Department of Internal Medicine Education, the First Affiliated Hospital of Guangxi Medical University, Nanning 530021, Guangxi, China.

\section{Received: 16 September 2018 Accepted: 3 April 2019}

\section{Published online: 23 April 2019}

\section{References}

1. Latib A, Colombo A. Bifurcation disease: what do we know, what should we do? JACC Cardiovasc Interv. 2008;1(3):218-26.

2. Leesar MA, Hakeem A, Azarnoush K, Thuesen L. Coronary bifurcation lesions: present status and future perspectives. Int J Cardiol. 2015;187:48-57.

3. Cohen DJ, Bakhai A, Shi C, Githiora L, Lavelle T, Berezin RH, Leon MB, Moses JW, Carrozza JP Jr, Zidar JP, Kuntz RE. SIRIUS Investigators. Cost-effectiveness of sirolimus-eluting stents for treatment of complex coronary stenoses: results from the Sirolimus-eluting balloon expandable stent in the treatment of patients with DeNovo native coronary artery lesions (SIRIUS) trial. Circulation. 2004;110(5):508-14.

4. Lee JM, Park KW, Koo BK, Kim HS. Stenting of coronary bifurcation lesions: a literature and technical review. Curr Cardiol Rep. 2015;17(6):45.

5. Colombo A, Bramucci E, Saccà S, Violini R, Lettieri C, Zanini R, Sheiban I, Paloscia L, Grube E, Schofer J, Bolognese L, Orlandi M, Niccoli G, Latib A, Airoldi F. Randomized study of the crush technique versus provisional sidebranch stenting in true coronary bifurcations: the CACTUS (coronary bifurcations: application of the crushing technique using Sirolimus-eluting stents) study. Circulation. 2009;119(1):71-8.
6. Erglis A, Kumsars I, Niemelä M, Kervinen $K$, Maeng M, Lassen JF, Gunnes $P$, Stavnes S, Jensen JS, Galløe A, Narbute I, Sondore D, Mäkikallio T, Ylitalo K, Christiansen EH, Ravkilde J, Steigen TK, Mannsverk J, Thayssen P, Hansen KN, Syvänne M, Helqvist S, Kjell N, Wiseth R, Aarøe J, Puhakka M, Thuesen L. Nordic PCI Study Group. Randomized comparison of coronary bifurcation stenting with the crush versus the culotte technique using sirolimus eluting stents: the Nordic stent technique study. Circ Cardiovasc Interv. 2009;2(1):27-34.

7. Chen SL, Xu B, Han YL, Sheiban I, Zhang JJ, Ye F, Kwan TW, Paiboon C, Zhou YJ, Lv SZ, Dangas GD, Xu YW, Wen SY, Hong L, Zhang RY, Wang HC, Jiang TM, Wang Y, Sansoto T, Chen F, Yuan ZY, Li WM, Leon MB. Clinical outcome after DK crush versus Culotte stenting of distal left Main bifurcation lesions: the 3-year follow-up results of the DKCRUSH-III study. JACC Cardiovasc Interv. 2015;8(10):1335-42.

8. Liberati A, Altman DG, Tetzlaff J, et al. The PRISMA statement for reporting systematic reviews and meta-analyses of studies that evaluate healthcareinterventions: explanation and elaboration. BMJ. 2009;339:b2700.

9. Baystrukov VI, Kretov El, Boukhris M, Osiev AG, Grazhdankin IO, Biryukov AV, Najjar H, Verin W, Zubarev DD, Naryshkin IA, Bogachev-Prokophiev AV, Mashayekhi K, Galassi AR, Prokhorikhin AA. A randomized trial of bifurcation stenting technique in chronic total occlusions percutaneouscoronary intervention. Coron Artery Dis. 2018;29(1):30-8.

10. Chen SL, Santoso T, Zhang JJ, Ye F, Xu YW, Fu Q, Kan J, Zhang FF, Zhou Y, Xie DJ, Kwan TW. Clinical Outcome of Double Kissing Crush Versus Provisional Stenting of Coronary ArteryBifurcation Lesions: The 5-Year Follow-Up Results From a Randomized and MulticenterDKCRUSH-II Study (Randomized Study on Double Kissing Crush Technique Versus ProvisionalStenting Technique for Coronary Artery Bifurcation Lesions). Circ Cardiovasc Interv. 2017;10(2)

11. Chen SL, Zhang JJ, Han Y, Kan J, Chen L, Qiu C, Jiang T, Tao L, Zeng H, Li L, Xia Y, Gao C, Santoso T, Paiboon C, Wang Y, Kwan TW, Ye F, Tian N, Liu Z, Lin S, Lu C, Wen S, Hong L, Zhang Q, Sheiban I, Xu Y, Wang L, Rab TS, Li Z, Cheng G, Cui L, Leon MB, Stone GW. Double kissing crush versus provisional stenting for left Main distal bifurcation lesions: DKCRUSH-V randomized trial. J Am Coll Cardiol. 2017;70(21):2605-17.

12. Galassi AR, Tomasello SD, Capodanno D, Barrano G, Ussia GP, Tamburino C. Mini-crush versus T-provisional techniques in bifurcation lesions: clinical and angiographic long-term outcome after implantation of drug-eluting stents. JACC Cardiovasc Interv. 2009;2(3):185-94.

13. Kim YH, Lee JH, Roh JH, et al. Randomized comparisons between different stenting approaches for bifurcation CoronaryLesions with or without side branch stenosis. JACC Cardiovasc Interv. 2015;8(4):550-60.

14. Higgins JP, et al. Assessing risk of bias in included studies, in Cochrane handbook for systematic reviews of interventions. Cochrane book series. 2008:187-241.

15. Chen SL, Sheiban I, Xu B, et al. Impact of the complexity of bifurcation lesions treated with drug-eluting stents: the DEFINITION study (definitions and impact of complEx bifurcation leslons on clinical outcomes after percutaNeous coronary IntervenTIOn using drug-eluting steNts). JACC Cardiovasc Interv. 2014;7(11):1266-76.

16. Généreux P, Kumsars I, Lesiak $M$, et al. A randomized trial of a dedicated bifurcation stent versus provisional stenting in the treatment of coronary bifurcation lesions. J Am Coll Cardiol. 2015;65(6):533-43.

17. Behan MW, Holm NR, de Belder AJ, et al. Coronary bifurcation lesions treated with simple or complex stenting: 5-year survival from patient-level pooled analysis of the Nordic bifurcation study and the British bifurcation coronary study. Eur Heart J. 2016;37(24):1923-8.

18. Zhang JJ, Tan H, Ye F, Tan HC, Chen SL. Bench test of bifurcation stenting techniques. J Clin Innov Cardiol. 2016;1:16-22.

19. Hildick-Smith D, de Belder AJ, Cooter N, Curzen NP, Clayton TC, Oldroyd KG, Bennett L, Holmberg S, Cotton JM, Glennon PE, Thomas MR, Maccarthy PA, Baumbach A, Mulvihill NT, Henderson RA, Redwood SR, Starkey IR, Stables RH. Randomized trial of simple versus complex drug-eluting stenting for bifurcation lesions: the British bifurcation coronary study: old, new, and evolving strategies. Circulation. 2010;121(10):1235-43.

20. Foin N, Alegria-Barrero E, Torii R, Chan PH, Viceconte N, Davies JE, Di Mario C. Crush, culotte, T and protrusion: which 2-stent technique for treatment of true bifurcationlesions? - insights from in vitro experiments and microcomputed tomography. Circ J. 2013;77(1):73-80.

21. Bundhun PK, Wu ZJ, Chen MH. Impact of modifiable cardiovascular risk factors on mortality after percutaneous coronary intervention: a 
systematic review and meta-analysis of 100 studies. Medicine (Baltimore). 2015;94(50):e2313.

22. Bundhun PK, Wu ZJ, Chen MH. Is there any significant difference in stent thrombosis between Sirolimus and paclitaxel eluting stents?: a systematic review and meta-analysis of randomized controlled trials. Medicine (Baltimore). 2016;95(5):e2651.

Ready to submit your research? Choose BMC and benefit from:

- fast, convenient online submission

- thorough peer review by experienced researchers in your field

- rapid publication on acceptance

- support for research data, including large and complex data types

- gold Open Access which fosters wider collaboration and increased citations

- maximum visibility for your research: over $100 \mathrm{M}$ website views per year

At $B M C$, research is always in progress.

Learn more biomedcentral.com/submissions 